\title{
Between Theory and Reality: The challenge of distinguishing between trafficked children and independent child migrants
}

\author{
Mike Dottridge
}

\section{Abstract}

The offence of child trafficking appears to have a clear definition in the UN Trafficking Protocol and in laws based on it. In practice, this is an illusion. This article reviews the experiences of three countries (Benin, the United Kingdom, and Vietnam), in two of which anti-trafficking laws and policies regard a broad swath of children who migrate to earn a living, without being subjected to coercion, as victims of trafficking. It questions whether the definitions in international law and in the laws of many countries of what constitutes the crime of trafficking committed against a child are appropriate to distinguish between adolescent migrants in general and those who are victims of crime (at the hands of a trafficker) in particular. It suggests that this is in part because there is no international understanding about the ages at which children habitually leave home to find work and what should be done to protect them when they do. It concludes that a possible result of considering a very broad range of children to be 'trafficked' is that measures to protect and assist those who suffer acute harm are inadequate.

Keywords: child trafficking, independent child migrants, child domestic work, vidomègon, cannabis cultivation

Please cite this article as: M Dottridge, 'Between Theory and Reality: The challenge of distinguishing between trafficked children and independent child migrants', Anti-Trafficking Review, issue 16, 2021, pp. 11-27, https://doi.org/10.14197/ atr.201221162

This is an open-access article distributed under the terms of the Creative Commons Attribution License (CC-BY). Under the CC-BY license, the public is free to share, adapt, and make commercial use of the work. Users must always give proper attribution to the authors and the Anti-Trafficking Review. 


\section{Introduction}

In November 2000, the United Nations (UN) adopted a convention and three protocols intended to facilitate action against transnational organised crime, including a protocol on human trafficking and another on helping migrants cross borders illicitly ('migrant smuggling'). Notwithstanding that international legal framework and its inclusion in national laws, governments, non-governmental organisations (NGOs) and the collective 'international community' have difficulty in coming to terms with the rights and needs of adolescents who work away from home, either in their own country or after crossing international borders. Although a vast proportion of the world's children start work before reaching adulthood, their rights at work are often poorly defined and the extra protection needed by those working away from home (by themselves) are scarcely recognisedmainly because of an assumption that children should be able to grow up with their parents and attend school until they reach adulthood. This assumption is exacerbated by the negative attitude of politicians in wealthier countries towards undocumented migrants from poorer countries, which denies the legitimacy of their efforts to migrate and earn a living. It labels independent child migrants as 'unaccompanied children' who require 'protection', meaning that they are likely to be prevented from earning money, even if they want to.

The information presented here about child migrants and trafficked children focuses on the experiences of three countries (Benin, ${ }^{1}$ the United Kingdom and Vietnam), in two of which anti-trafficking laws and policies have come to regard a broad swath of children who migrate to earn a living, without being coerced, as victims of trafficking. In the first case (Benin), most of the children concerned are girls who work away from home in their own country, while in the second (Vietnamese children who travel to the UK), most are boys. The data was gathered over a quarter century, partly in the course of monitoring the effects of projects designed to stop human trafficking (in Benin and Vietnam) and also from secondary sources. The author visited Benin several times in the 1990s and between 2005 and 2010 to observe or evaluate the efforts of NGOs trying to prevent child trafficking. He visited Vietnam twice for the purpose of evaluating regional anti-trafficking programmes and was subsequently involved in compiling a bibliography of publications about human trafficking in the country. While developing methods for monitoring official responses to human trafficking, he has monitored publicly available information about Vietnamese adolescents involved in undocumented migration to the United Kingdom (UK).

1 The references to 'Benin' in this article are all to the Republic of Benin in West Africa, not to the city of Benin in neighbouring Nigeria, which is also the place of origin of substantial numbers of trafficked women as well as girls. 
This article explores whether the definitions in international and national laws of what constitutes the crime of trafficking committed against a child are appropriate and adequate to distinguish between adolescent migrants in general and those who are victims of crime (at the hands of a trafficker) in particular. I argue that they are flawed and that there is a virtually unbridgeable gap between the international consensus about when children can work away from home and the reality lived by millions of children. ${ }^{2}$ Categorising adolescent children who migrate to earn money away from home as victims of a criminal activity ('trafficking') is probably not an appropriate way of addressing large-scale migration. Moreover, inconsistencies exist in the way that national definitions of the crime of human trafficking are applied, both for prevention and protection purposes.

\section{The Theoretical Framework: International and national law}

The internationally recognised legal definition of trafficking in persons is in the UN Protocol to Prevent, Suppress and Punish Trafficking in Persons, Especially Women and Children, supplementing the UN Convention against Transnational Organized Crime (2000). It defines the crime of trafficking in cases involving adults in terms of a set of actions (such as recruitment or receipt of a person) and a set of abusive means used to achieve these actions (such as the threat or use of force), all carried out for the purpose of certain forms of exploitation. The Protocol lists categories of exploitation that countries ratifying it are expected to identify as purposes of trafficking, such as the exploitation of the prostitution of others, forced labour, and practices similar to slavery. It also allows for other types of exploitation to be added.

In the case of anyone under 18 years, the Protocol modifies the way the crime is defined, saying there is no need for abusive means to be used, for example when recruiting a child, for it to be considered a trafficking offence. In short, as far as children are concerned, the UN Trafficking Protocol defines as a trafficking offence any situation in which a young person is recruited, transported, transferred, harboured or received for the purpose of exploitation, whether the recruitment involves luring or abducting a child or the child is recruited

2 The International Labour Organization's published estimates of the number of children in child labour indicate that in 2016 there were 152 million child labourers in the world, with almost half in 'worst forms' of child labour and more than four million reported in forced labour (ILO, Global Estimates of Child Labour: Results and trends 2012-16, Geneva, 2017). The ILO's review of trends since 2000 suggests that, if the pace of the reductions achieved between 2012 and 2016 is maintained, by 2025 there will still be 121 million child labourers (ILO, Ending Child Labour by 2025: A review of policies and programmes. Executive summary, Geneva, 2018). 
voluntarily. If a child is recruited or moved with their agreement, the key distinction between a case of trafficking and one of recruitment into acceptable employment focuses on the nature of the young person's subsequent experience at work or while being exploited: whether the child is (or is intended to be) subjected to one of the forms of exploitation listed by the Protocol. Some of these, such as forced labour, are not defined clearly when it comes to children. ${ }^{3}$

\section{Complex Realities}

In Europe and elsewhere, it was apparent before the year 2000 that children were being moved between and within countries for a variety of exploitative purposes (so, under the definition in the new Protocol, they were being trafficked). Nevertheless, legislators, policymakers, police, prosecutors, and childcare professionals all assumed, initially, that trafficking in children chiefly involved recruiting girls to make money from engaging in commercial sex. In practice, other exploitative purposes included begging, pickpocketing, and working in what the International Labour Conference labelled 'worst forms of child labour' (in ILO Convention No. 182, 1999). Some earned money for their parents and others handed their earnings to someone else. The diversity of the licit or illicit ways in which children earned money brought assumptions made by officials into question. Nevertheless, for many years officials around the world continued to regard the children who were involved in these activities as criminals, rather than victims of crime. For example, prior to 2003, officials in Greece detained Albanian children who were found begging for money in public, perceiving them to be in Greece illegally, causing a public nuisance, and committing other offences. ${ }^{4}$

A common pattern was that national authorities acknowledged that children who were their own nationals were trafficked and exploited overseas but were reluctant to acknowledge that foreign children were trafficked into their country,

3 An additional complication concerns the age at which a child is recruited, for international standards stress the importance of each country specifying a minimum age for entry into employment (set at 14, 15 or 16 years). Although the ILO intimated in 2009 that recruiting children to work before the minimum age should be regarded as 'trafficking', this is not part of the UN Protocol's definition of child trafficking (see ILO, UNICEF and UN.GIFT, Training Manual to Fight Trafficking in Children for Labour, Sexual and Other Forms of Exploitation, Textbook 1: Understanding child trafficking, 2009). Further, public opinion and law enforcement agencies in many developing countries do not accord the same importance to respecting the minimum age set by national law and international conventions, which international organisations are bound to use as their point of reference.

4 Terre des Hommes Foundation, The Trafficking of Albanian Children in Greece, Lausanne, 2003. 
or that children were being trafficked within the borders of their own country. For example, the Vietnamese authorities expressed concern that Vietnamese girls and women who married foreigners were victims of trafficking. They were also concerned about adolescent Vietnamese girls in brothels in neighbouring Cambodia at the beginning of the century. However, they did not regard Cambodian children who were brought to beg in Ho Chi Minh City as 'trafficked'. 5 Although perceptions of what 'trafficking' involves have changed in Vietnam in the past decade, law enforcement officials and policymakers there (as elsewhere) have found it difficult to assess which children should be viewed as 'trafficked' and what, if anything, should be done about them.

\section{How Three Countries Have Defined Cases of Child Trafficking}

\section{The Republic of Benin (West Africa)}

The Republic of Benin acquired notoriety as a source of trafficked children in April 2001, only months after the UN Trafficking Protocol was adopted. A ship carrying undocumented West African migrants, including dozens of children, to oil-rich Gabon was turned back by the Gabonese authorities. When nothing was heard from the ship subsequently, media speculated that it had disappeared and that 'child slaves' on board might have been thrown overboard. This apparent disappearance occurred only a few months after a television documentary shown in the UK reported that child migrants were being subjected to slavery on cocoa farms in Côte d'Ivoire, so a British government minister suggested (mistakenly) that the children on the Etireno were destined to work on cocoa farms. ${ }^{6}$ When the ship arrived back at its port of departure, Cotonou in Benin, 43 children disembarked: 23 were aged between five and 14, while 17 were older boys. ${ }^{7}$ All were referred for assistance to local NGOs. Western journalists reported that there were fewer children than expected and they did not look like slaves.

Under pressure from donors and international organisations from 2001 onwards, Benin adopted a series of laws on child trafficking, though none has been based on local assessments of what constitutes unacceptable forms of work for children. Consequently, when cases of severe maltreatment of child workers

5 F M David, A Gallagher, P Holmes and A Moskowitz, Progress Report on Criminal Justice Responses to Trafficking in Persons in the ASEAN Region, ASEAN Secretariat, Jakarta, 2011.

6 C Harman, A Bar Too Far-Chocolate and child slavery, Just Food, 20 April 2001, retrieved 6 January 2020, https://www.just-food.com/analysis/a-bar-too-far-chocolateand-child-slavery_id93799.aspx.

7 M Dottridge, Kids as Commodities? Child trafficking and what to do about it, Terre des Hommes, Geneva, 2003, p. 17. 
were revealed, the term 'trafficking' was invoked to accuse those who recruited children and found them jobs of being criminals, rather than concentrate on changing the behaviour of employers (in the case of child domestic workers) and the views of the general public on what is or is not acceptable treatment of an adolescent or younger working child. In a developing region where hundreds of thousands (possibly millions) of children leave home each year to earn a living elsewhere, the concept of 'migrant smuggling' has not been helpful, for in this region with international borders separating people belonging to the same ethnic group, it is not necessarily crossing an international border that puts a young migrant at greater risk of being exploited or abused. ${ }^{8}$

One consequence of the Trafficking Protocol was that some donors initiated programmes on the assumption that all independent child migrants were victims of traffickers and that those responsible for helping them travel safely or employing them should be prosecuted. This approach may have had good intentions (to stop children living and working in abusive situations). However, it was largely counterproductive for many of the children concerned. By failing to distinguish between children who wanted to earn their living and who were working in tolerable circumstances, on the one hand, and those who were being badly treated or subjected to cruel, inhuman, or degrading treatment (and who were in urgent need of protection), on the other, donors and the international agencies they supported may have actually increased the amount of suffering that occurred.

The different concepts of child migration and child trafficking were more confused in Benin than in many other countries. In the southern part of Benin, girls as young as ten routinely left home to provide assistance in another household. This practice was known as vidomègon, and was regarded as legitimate by local people, even though some children were treated as skivvies by their employers. The abuse of child domestic workers who 'live-in' with their employers began to be documented systematically in the 1990s in Benin, along with neighbouring Nigeria and Togo and countries to which children from Benin were taken to work, such as Gabon. Researchers noted that each year, many hundreds of children from Benin were taken across the sea to work for West African households in Gabon, often in dangerous conditions in open canoes. ${ }^{9}$ When the first findings of research concerning foreign-born working children in Gabon were published in 2000, all 133 West African girls and one boy

8 Such divisions are also found in other regions, for example dividing a single ethnic community between Bangladesh and India.

9 See A F Adihou, Résumé du Rapport Final sur le Trafic des Enfants entre le Bénin et le Gabon, Anti-Slavery International and Enfants solidaires d'Afrique et du monde (ESAM), 2000 . 
who were interviewed in Gabon were described as 'trafiquées'.

In 2003, a further child trafficking scandal engulfed Benin when 261 children from Benin were found working in a gravel quarry outside the city of Abeokuta in neighbouring Nigeria. The Nigerian authorities said they had been 'trafficked' and repatriated them amidst much publicity. However, it turned out that 26 of those returned to Benin as 'children' were actually young adults aged over 18, while 48 others were aged 16 or 17 (old enough to be legally employed, even if quarry work was regarded as inappropriate work for young people of their age). None of these 74 young people was offered the option of remaining in Nigeria and continuing to work there, despite a regional treaty recognising their right to do so. They were bundled out of Nigeria along with the younger children found alongside them. Soon after they reached home, some of the repatriated children were observed to leave again, apparently determined to continue their quest for an income elsewhere. ${ }^{11}$

These events in Benin prompted two different responses. At regional level in West Africa, a group of NGOs and international organisations decided to collect fuller information about independent child migrants in the region and to identify better ways of describing their situation and protecting them, rather than assuming they were being trafficked. This took several years and a great deal of discussion among the organisations involved. ${ }^{12}$

At national level in Benin, the authorities came under pressure from abroad, notably from the United States (US) and the European Union, to adopt a new law to punish traffickers. In theory, Benin's authorities could have found out what sorts of work the general public thought were acceptable for children to engage in when they left home, and a new law could have focused on the forms of ill-treatment and exploitation that the public regarded as unacceptable, or on jobs that caused children particular harm. This option would have required the authorities to assert their independence with respect to influential donors

10 This was translated incorrectly into English as 'trafficked', although the French term refers to people who are 'smuggled'; 'traite' is the correct translation of human trafficking as defined in the UN Trafficking Protocol. However, this usage and error were common in West Africa and other regions prior to 2000.

11 O Feneyrol, Les Petites Mains des Carrières de Pierres. Enquête sur un trafic d'enfants entre le Bénin et le Nigéria, Terre des Hommes Foundation, 2005.

12 The resulting report contains detailed information on popular perceptions of children working away from home in West Africa and what can be done to protect and support them. See O Feneyrol, Quelle Protection pour les Enfants Concernés par la Mobilité en Afrique de l'Ouest et du Centre? Nos positions et recommandations, Projet régional commun d'étude sur les mobilités des enfants et des jeunes en Afrique de l'Ouest: African Movement of Working Children and Youth, ENDA Jeunesse Action, ILO, IOM, Plan International, Save the Children, Terre des Hommes and UNICEF, Dakar, 2011. 
and powerful countries, such as the US which had adopted its own law against trafficking in persons in 2000, requiring the US government to assess annually whether other countries were taking adequate action to stop trafficking in persons. Regrettably, but not surprisingly, Benin's legislators took a second option, using the wording from definitions offered by UN organisations and adopting measures which satisfied the demands of donors, even though these were unlikely to be implemented. In 2006, Benin adopted a law to stop anyone under 18 from moving away from home without an official permit (Law 2006-04 concerning the Movement of Minors and the Suppression of Child Trafficking in Benin). This introduced a very broad definition of a child trafficking victim as 'any child migrant who is not attending school and who is living in a household without his/her own parents or guardian and who has been brought there by someone who made a profit', that is to say, including independent child migrants who were assisted in finding a job by a person who was remunerated for their services, regardless of whether the child and their parents found these services helpful. It also introduced a permit system which was difficult for ordinary people to use. ${ }^{13}$

A study published in 2007 by Benin's Ministry of Family and Children and UNICEF estimated that over 40,000 Beninese children were 'victims of trafficking' according to the new (2006) law and that each year almost 15,000 children were trafficked. ${ }^{14}$ The implication was that a massive two percent of the country's children were in the hands of criminals, even though the employment of children as live-in domestics and in many other jobs was widely regarded as acceptable. The estimate of 40,000 was repeated by the media and in international conferences for most of the following decade. ${ }^{15}$

The 2007 study noted that just 2,066 children out of 40,000 were 'moved by a broker' while the 38,000 others migrated voluntarily but ended up being 'exploited'. In 40 per cent of the cases, exploitation was assumed to occur because the child concerned was employed as a live-in domestic. Ironically, the study omitted all mention of adolescent girls reported several years earlier to be earning money from commercial sex for 'pimps' and traffickers in Cotonou: the

13 The negative implications for children of Benin's policies on child trafficking are examined in detail in N Howard, Child Trafficking, Youth Labour Mobility and the Politics of Protection, Palgrave Macmillan, London, 2017.

14 Centre de Formation et de Recherche en matière de Population (CEFORP), Etude Nationale sur la Traite des Enfants. Rapport d'analyse, Ministère de la Famille et de l'Enfant et l'UNICEF, Cotonou, 2007.

15 In 2015, for instance, in a report for the International Labour Conference and a broadcast by Radio France International (RFI): D Bousquet, 'Les Enfants Esclaves au Bénin', RFI, 16 April 2015, retrieved 4 March 2021, http://www.rfi.fr/fr/ emission/20150416-benin-esclavage-enfants-passerelle. 
unpublished research, of which the authorities were aware, identified adolescent Nigerian girls in Cotonou who had been brought there from Nigeria's Edo State.

Gabon adopted a law prohibiting the employment of children under 15 as early as 2004 but little was done to implement it. The journeys involving adult and child migrants from Benin across the Bight of Benin to Gabon and neighbouring Equatorial Guinea continued, despite new laws in Benin and Gabon, and remained just as dangerous: for example, in March 2015, a boat carrying more than 150 undocumented migrants to Gabon was reported by Reuters to have capsized off the coast of Nigeria, drowning 45. A survivor said that many on board were women and children from West Africa.

For a decade and a half Benin's anti-trafficking laws focused specifically on children employed away from home, without the practice of employing vidomègon being prohibited or regulated and without significant measures being taken to improve the treatment of child domestic workers. Each year, the US Trafficking in Persons Report (hereafter: TIP Report) suggested Benin's laws and policies were flawed and needed to conform more closely with the provisions of the US's own law of 2000, outlining standards that US legislators expected every country in the world to observe. Finally, in 2018, Benin adopted a new penal code, defining (in article 499) a crime of human trafficking when adults are the victims, rather than only children. The wording of the offence, including the forms of exploitation identified as 'purposes of trafficking', is broadly in line with the UN Trafficking Protocol's definition. However, it includes an additional provision concerning children, defining any case in which a child's natural parent or guardian makes use of the services of a child under 14 years of age for profit as a form of exploitation linked to trafficking and therefore an offence.

Was the use of criminal law ever viable to stop both extreme cases of child exploitation (whether in Benin or abroad) and more conventional cases of child employment regarded by much of the population as acceptable or even beneficial to children? The Benin authorities reportedly told US diplomats in 2020 that 44 cases of child trafficking had resulted in prosecutions in 2018 and that a further 28 suspected child traffickers had been prosecuted in $2019 .{ }^{16}$ If there were indeed 15,000 children trafficked each year, or even only 1,500, this meant that the criminal justice system responded to only a handful of cases. The US authorities appeared relatively satisfied in their 2020 TIP Report, as they noted a substantial increase in the previous year in prosecutions of suspected traffickers of adults. However, the Benin experience demonstrates that using criminal law to address a pattern of child labour, including children working away from home, is not an effective or efficient strategy when the numbers are large and when

\footnotetext{
16 US Department of State, Trafficking in Persons Report, Washington DC, 2020, p. 113.
} 
doing so flies in the face of public opinion. The employment of vidomègon has continued to prompt criticism in media abroad. However, media publicity and references in international reports have brought few benefits to the children concerned. The conventions and protocols adopted at ILO and UN conferences ${ }^{17}$ have not led to improvements in the lives of young people, such as better working conditions or less harsh treatment at work, which they were entitled to expect.

\section{Children Moving from Vietnam to the United Kingdom: The situation in Vietnam}

The second pattern reviewed here concerns Vietnamese children who travel to the UK to earn money. This requires a brief review of the situation in Vietnam, as well as the UK. Vietnam is one of the few countries in the world that does not regard 16- and 17-year-old adolescents as children (adulthood is reached at 16 years of age, rather than 18, the age stipulated by the UN Convention on the Rights of the Child). This introduces a disconnect between the way the authorities in Vietnam and those in other countries to which Vietnamese adolescents migrate view cases of 16- and 17-year-olds and how the authorities should respond.

Vietnam initiated action against human trafficking early this century, joining the Coordinated Mekong Ministerial Initiative Against Trafficking (COMMIT) set up in 2004 with other Greater Mekong Subregion states. It launched its first national plan against trafficking in women and children the same year (setting out activities from 2004 to 2010). It signed an initial bilateral Memorandum of Understanding about human trafficking with neighbouring Cambodia in 2005, followed by others with Thailand and China. However, the authorities assumed that human trafficking was primarily about prostitution which had been categorised as a 'social evil' since 1975. Recruiting a woman into prostitution was an offence and the penal code also prohibited 'trading in children', which was interpreted to mean buying or selling a child (under 16) for profit. Vietnam also had strict laws against unofficial emigration, such as Penal Code article 275, making it an offence to organise or force people to run away abroad or stay in foreign countries.

In practice, prior to 2010, the Vietnamese authorities focused on two traffickingrelated issues: first, marriages contracted by Vietnamese women outside Vietnam, which they regarded with suspicion ${ }^{18}$ (in China many Vietnamese were forced or tricked into marriage in rural areas where there were shortages of women of marriage age); secondly, adolescent girls and women who were taken to brothels

17 Such as the UN Convention on the Rights of the Child (1989) and the ILO's Convention No. 182 on Worst Forms of Child Labour (1999).

18 See D Bélanger, 'Marriages With Foreign Women in East Asia: Bride trafficking or voluntary migration?', Population \& Societies, no. 469, 2010, pp. 1-4, https://corpus. ulaval.ca/jspui/handle/20.500.11794/11308. 
in Cambodia and China (on the outskirts of Phnom Penh and in Hekou in China's Yunnan province). This initial focus intensified with the distribution of an InterMinisterial Circular in 2008, outlining procedures for statutory agencies to identify and protect girls or women who had been trafficked. ${ }^{19}$ The implications were that boys and men were not recognised as victims of traffickers, that situations of exploitation for anything except prostitution did not involve trafficking (even when the workers involved were subjected to harsh abuse), and that cases involving internal trafficking did not merit attention.

The approach changed from 2010 onwards, when the authorities modified their understanding of trafficking. Vietnam adopted a new anti-trafficking law in 2011 and acceded to the UN Trafficking Protocol in 2012, by which time the author had visited Hanoi twice (in 2005 and 2011) to evaluate anti-trafficking programmes and confirmed on both occasions that officials with anti-trafficking responsibilities were largely unaware of any Vietnamese being trafficked to Europe. The wording of the 2011 Law on Prevention and Suppression Against Human Trafficking resembled the text of the UN Protocol, listing a series of 'prohibited acts' that include trafficking in persons and also recruitment, transportation, harbouring, transfer and receipt of persons for the purposes of sexual exploitation, forced labour, organ removal or 'other inhuman purposes'. The new law seemed more straightforward than the UN Protocol, in that it made no reference to abusive means (to carry out the actions deemed to constitute trafficking). The law consequently does not differentiate between adults and children as victims in the way that the offence is defined (as the UN Protocol does).

The 2011 law contained provisions to protect trafficking victims. Article 24 requires the authorities to identify a relative of a trafficked child who is under 16 to come and fetch her (or him) or, in the absence of relatives, to find someone else who can accompany the child to their habitual residence. Alternatively, the authorities can refer a child who is 'helpless' and has no place of residence to a state-run institution or a residential facility run by an NGO that supports victims. In practice, the children referred to residential institutions in Vietnam are girls who have experienced commercial sexual exploitation abroad, not unaccompanied Vietnamese children found in Europe, according to NGOs. Indeed, virtually no data have been made public about children identified as 'trafficked' in Europe and subsequently returned to Vietnam, either by countries from which children have been returned or by the authorities in Vietnam.

19 Guidelines on Process and Procedures of Identification and Reception of Trafficked Women and Children from Abroad, Inter-Ministerial Circular 03/2008/TTLC-MPS-MOD-MOLISA. 
Like Benin, Vietnam has seen large numbers of children under 16 recruited to work away from home in other parts of the country (mainly in cities). However, the response has been quite different to Benin's, with the authorities taking much less interest in such cases, whatever the nature of the children's work or exploitation. This was made easier because some of the NGOs providing assistance to working children, child beggars, and adolescent girls in the commercial sex sector suspected that the authorities would punish them if they publicised the cases.

\section{Children from Vietnam Arriving in the United Kingdom}

Developments on the other side of the world in the United Kingdom ran to some extent in parallel. The UK signed the UN Trafficking Protocol in 2000 and ratified it in 2006. Initial amendments to UK law were piecemeal, based on an assumption that trafficking was an immigration offence (involving foreign nationals brought to the UK) that occurred mainly to make money from commercial sex. This changed after December 2008, when the UK ratified the Council of Europe Convention on Action against Trafficking in Human Beings (2005), which required state parties to take a broader approach and to protect the rights of trafficking victims. Public opinion in the UK was also shocked by the drowning of 23 cockle pickers in 2004, all believed to be undocumented Chinese migrants, with the result that the UK adopted a law to regulate the activities of 'gangmasters' (individuals contracted to provide 'gangs' of workers for a specified time).

More relevantly, a new wave of Vietnamese irregular migration into the UK started early in the twenty-first century. Most Vietnamese arriving in the UK were men and adolescent boys: the UK authorities regarded anyone under 18 as a child, with particular protection rights. The occupation for Vietnamese boys (and adults) that received most publicity in the UK was that of 'cannabis gardeners' looking after illegally-grown cannabis, initially in houses which appeared to be under repair (windows and doors were shuttered and plants grown under artificial light), and later, on a larger scale, at underground facilities and farms. Undocumented Vietnamese adolescents and adults also found work in nail bars or restaurants serving Vietnamese food.

The British authorities investigated the illicit migration routes from Vietnam to Europe and the UK and how migrants earned a living after their arrival. In 2007, the UK government set up two new institutions: the first to investigate cases of human trafficking involving adults, and the second, the Child Exploitation and Online Protection (CEOP) Centre, with a mandate on child trafficking (as well as online abuse). CEOP published its first report about child trafficking in the UK in 2007, noting that 22 Vietnamese children had been identified in 2006 as trafficking victims; half of them were boys, the other half girls. Six had been arrested on cannabis farms. The report commented that Vietnamese 
migrants were 'transported... in debt bondage' ${ }^{20}$ A further CEOP report in 2009 noted that young Vietnamese aged between 15 and 17 who had been found by police in the UK had little if any contact with the outside world; they were only known to their captors'. ${ }^{21}$ Already in 2009, CEOP reported that senior police managers and the prosecution service had issued guidance on the treatment of children found in such criminal enterprises to ensure that no child is brought before the courts where the crime committed is a direct result of their trafficking'. Between 2010 and 2013, the prosecution services in the various parts of the UK provided advice to prosecutors about the 'non-punishment principle' (that someone who was trafficked should not be charged or prosecuted for the illegality of their presence in a country or their involvement in unlawful activities to the extent that such involvement was a direct consequence of being trafficked). ${ }^{22}$ However, the guidance took a long time to filter down to frontline police and prosecutors as well as, crucially, to the lawyers representing detained Vietnamese children in local courts, who went on advising their clients to plead guilty to minor offences rather than risk being referred for trial on more serious charges.

In summary, although some parts of the UK's criminal justice system had decided by 2010 that Vietnamese children arriving clandestinely in the UK were trafficking victims, others continued to view them as criminals and sent them to prison (to young offenders' institutions). Penalising children in this way was repeatedly challenged by child rights defenders (particularly one NGO, ECPAT UK), but the authorities continued to prosecute and convict Vietnamese children until 2013, when the Court of Appeal (Criminal Division) of England and Wales reviewed four unconnected cases of three adolescents and one adult woman, all of whom had been convicted of offences despite being thought to have been trafficked. The three adolescent boys had been found on cannabis farms. The Court of Appeal quashed all four convictions on the grounds of abuse of process as the courts had not taken into account that they had been trafficked. It did not assert simply that people who were trafficked should not be prosecuted or punished. Rather, it concluded that, ' $[t]$ he criminality, or putting it another way, the culpability, of any victim of trafficking may be significantly diminished, and in some cases

20 A Kapoor, A Scoping Project on Child Trafficking in the UK, CEOP (produced on behalf of the Home Office and the Border and Immigration Agency), London, 2007, p. 32. CEOP, Strategic Threat Assessment. Child Trafficking in the UK, London, April 2009, p. 46.

22 P Burland, 'Still Punishing the Wrong People: The criminalisation of potential trafficked cannabis gardeners', in G Craig, A Balch, H Lewis and L Waite (eds.), The Modern Slavery Agenda. Policy, politics and practice in the UK, Policy Press, Bristol, 2019, p. 168. Finally, in February 2021, the European Court of Human Rights, in its judgment VCL and $A N v$. the United Kingdom, concluded that the UK authorities had failed to adequately protect two Vietnamese youths who pleaded guilty in 2009 to drug-related offences. Even though they were recognised officially as trafficking victims, the Prosecution Service maintained that it had been correct to prosecute and punish the youths. 
effectively extinguished, not merely because of age (always a relevant factor in the case of a child defendant) but because no realistic alternative was available to the exploited victim but to comply with the dominant force of another individual, or group of individuals. ${ }^{, 23}$

In the UK's case, it was consequently not just the way that the crime of child trafficking was defined in law that led to Vietnamese children being regarded as trafficking victims. It was the finding of specialist anti-trafficking agencies and the courts. From 2014 onwards, the number of people referred to the UK's National Referral Mechanism (NRM) as possible trafficking victims climbed steadily, from 2,238 in 2014 to 10,627 in 2019. ${ }^{24}$ In 2015, out a total of 3,262 people referred to the NRM, 248 were children from Vietnam (along with 230 Vietnamese adults), accounting for about one quarter of the children referred to the NRM. By 2019, this number had increased to 427 children. The precise number of children who were eventually recognised by the authorities to be victims of trafficking was not clear, for they sometimes took several years to make a decision and the authorities eventually stopped publishing the results of NRM decisions. However, a 2017 study for the UK's Independent Anti-Slavery Commissioner noted that out of 1,747 Vietnamese nationals who had been referred to the NRM between 2009 and 2016, 370 (twenty-one per cent) had been 'officially' recognised as trafficking victims. Of these, almost half were reported to be between 14 and 16 years at the time they were referred to the NRM. ${ }^{25}$ The same study reported that 198 out of the 370 had been subjected to 'labour exploitation', of whom 77 boys and 38 adults had been cultivating cannabis.

Meanwhile, relatively few people in the UK have been prosecuted for trafficking Vietnamese children (or adults) and few convicted in Vietnam of trafficking children to the UK, despite a series of agreements since 2009 between the two countries. Children identified as 'trafficked' by the UK authorities are usually allowed to remain in the country until they reach 18 . There have been no reports of the Vietnamese authorities assisting trafficked children who have been returned from the UK, although a decade ago there were unofficial reports that some children had been returned. When Vietnamese owners of a nail bar

23 L, HVN, THN, and T v. R [2013] EWCA Crim 991, para. 13.

24 Statistics issued by the UK Home Office, 'National Referral Mechanism statistics UK: End of year summary 2019', 2 April 2020, https://www.gov.uk/government/ statistics/national-referral-mechanism-statistics-uk-end-of-year-summary-2019.

25 D Silverstone and C Brickell, Combating Modern Slavery Experienced by Vietnamese Nationals en Route to, and Within, the UK, Independent Anti-Slavery Commissioner, London, 2017, p. 7. 
in Bath were tried for trafficking in 2018, the children whom they were said to have exploited were not present as witnesses. Indeed, despite comments from the judge that adolescents had been treated as commodities and exploited for 'pure economic greed', there were some signs that the migrants concerned were working illicitly to compensate the bar owners for their temporary upkeep, while they sought longer-term and better remunerated work. ${ }^{26}$ There was repeated confirmation that Vietnamese adolescents who were earning a living illicitly felt under pressure to continue doing so, for when they were 'rescued' by the police and put into temporary accommodation, many walked out. ${ }^{27}$ Despite the information at their disposal about the system of credit used by people in Vietnam to finance journeys of both adults and children to the UK, the British authorities took no specific action to alleviate the pressure that the migrant children's debts imposed on them to start earning money again (rather than remaining in local authority accommodation without earning anything).

Whether Vietnamese migrants identified in the UK as undocumented are regarded as victims of traffickers or not, the numbers referred in recent years to the NRM and asylum system confirm that until late 2019 there was a pattern of irregular migration to the UK, of both adults and adolescents, with some migrants able to access official procedures that allowed them to remain in the UK, either for a few years or permanently. The British authorities declared that they wanted to end this pattern and partnered with both the Vietnamese authorities and law enforcement agencies in other parts of Europe to reduce the number of arrivals. However, little had been achieved by mid-2019, even though an unofficial transit centre for undocumented Vietnamese migrants outside the French city of Lens that had been tolerated for some years was bulldozed in $2018 .^{28}$

A major tragedy in October 2019 led to at least a temporary pause to this migration corridor. A lorry arriving in England from Belgium was found to contain the corpses of 39 Vietnamese migrants, three of them under 18 and seven others aged 18 or 19 . The discovery was followed by the arrest of the

26 BBC television, The Prosecutors. Series 2:2. Modern-Day Slavery, broadcast on 9 August 2018, https://www.bbc.co.uk/iplayer/episode/b0bfdn7h/the-prosecutors-series2-2-modern-day-slavery.

27 N Finch, Lighting the Way: Steps that lawyers, legal guardians and child trafficking advocates in the UK can take to better identify and protect children who may have been trafficked, ECPAT-UK, London, 2017.

28 No Author, 'A Angres Comme Ailleurs, la Politique D’Expulsion Se Poursuit!', La Cimade, 27 April 2018, retrieved 4 March 2021, https:/ /www.lacimade.org/a-angrescomme-ailleurs-la-politique-dexpulsion-se-poursuit. 
lorry driver and others in the UK and Ireland. ${ }^{29}$ Six people were eventually convicted in the UK in connection with the deaths, three for manslaughter and for unlawfully smuggling people into the UK, but none for human trafficking. Four people were convicted in Vietnam for facilitating the illicit emigration of one of those who had died. In May 2020, separate arrests of 26 people suspected of facilitating the passage of other undocumented migrants from Vietnam were announced in Belgium and France. The 39 deaths shocked the public in Vietnam's Nghe An and Ha Tinh provinces, from where most of the dead originated. In the first half of 2020, observers speculated that this would deter further largescale emigration to the UK. Nevertheless, during the first nine months of 2020 Vietnamese migrants suspected of being trafficking victims continued to be referred to the UK's NRM in considerable numbers and were reported by the authorities to be the third-highest represented nationality after UK nationals and Albanians. ${ }^{30}$ However, the statistics available did not indicate how many had reached the UK after October 2019.

\section{Conclusion}

This article has summarised two quite different patterns of child migration, both of which have been labelled as 'child trafficking'. It sought to find out if the definition of the crime of human trafficking has helped distinguish between adolescent migrants in general and those who are specifically victims of trafficking offences. It noted a tendency by the authorities in different countries to apply very general assumptions - for example, that all vidomègon in Benin or all undocumented Vietnamese children engaged in working illegally in the UK have been trafficked. At the same time, relatively few of the brokers and employers concerned have been convicted of trafficking children, while in the case of undocumented migration from Vietnam to the UK, some have been convicted for facilitating illicit migration.

In none of the three countries has the criminal justice system yet proved effective in addressing the patterns of child migration and the exploitation involved. Labelling the pattern that brings hundreds of Vietnamese adolescents to the UK

29 See Essex Police, 'Investigation launched after 39 people found dead in lorry trailer', 23 July 2020, retrieved 4 March 2021, http:/ /web.archive.org/web/20210116104757/ https://www.essex.police.uk/news/essex/news/news/2019/october/murderinvestigation-launched-after-39-people-found-dead-in-lorry-container; and Essex Police, 'Two guilty for the manslaughter of 39 Vietnamese men, women and children', 21 December 2020, https://www.essex.police.uk/news/essex/news/brought-tojustice/2020/december/men-jailed-for-92-years/melrose-title.

30 UK Home Office, 'National Referral Mechanism Statistics UK', Quarters 1, 2 and 3 (January to March 2020; April to June 2020; and July to September 2020). 
each year as 'trafficking' and expecting British or Vietnamese police to provide the response seems just as unrealistic as the expectation that entrenched patterns of child migration and employment in West Africa will stop because new laws are adopted. In effect, the international community has been hiding its head in the sand and expecting miracles, rather than working seriously to create a brighter future for young people - a future in which they do not have to travel to the other side of the world to work for criminals or subject themselves to voluntary or involuntary servitude to earn money for themselves and their families. Instead, they should be able to earn a living in decent work in their own country, or, if this remains impossible, to migrate in circumstances that guarantee their safety and have their rights as adolescent workers protected while they work abroad.

In the UK, the 'trafficked' label has been significant for the children concerned, in that it confers an element of 'protection' (allowing officially recognised trafficking victims to stay in the UK until they reach 18), though this does not appear to be regarded as a substantial advantage by the many Vietnamese adolescents who walk out of care to resume earning. In Benin and Vietnam, the assertion that children are 'trafficked' has not resulted in the protection of many of the children concerned. Indeed, it may have created a false sense that the criminal justice system will provide a solution to patterns of exploitation, when actually it does not—implying that quite different initiatives are required.

Alternatives to invoking criminal law and using the term 'trafficking' are available, such as the ILO's Convention 182 on worst forms of child labour, but these also seek to put an immediate stop to the pattern of migration and exploitation, rather than bring about gradual change by using economic incentives and influencing social norms. In the author's view, a radical rethink is required: one that recognises that it may well be in the best interests of some children to leave home and start earning well before they reach 18. In these circumstances, it should surely be possible to offer meaningful alternatives to more young people in the places from which significant numbers of them migrate. It is also high time that government and NGO responses to child trafficking be coordinated much more systematically with other measures concerning social and economic development.

Mike Dottridge is an author and consultant on human rights and human trafficking issues. He was director of Anti-Slavery International from 1996 to 2002. He drafted a reference guide on UNICEF's Guidelines on the protection of the rights of child victims of trafficking (2006) and is the author of numerous articles, reports, and book chapters on both child labour and child trafficking. Email: mikedottridge@btopenworld.com 